\title{
La justicia alternativa como derecho humano
}

\section{Alternative justice as a human right}

DOI: https://doi.org/10.17981/juridcuc.15.1.2019.10

Fecha de Recepción: 20/07/2019 Fecha de Aceptación: 16/09/2019

\author{
Francisca Silva Hernández \\ Universidad Juárez Autónoma de Tabasco (México) \\ francisca.silva@ujat.mx
}

Germán Martínez Prats

Universidad Juárez Autónoma de Tabasco (México)

germanmtzprats@hotmail.com

Para citar este artículo:

Silva, F. y Martínez, G. (2019). La justicia alternativa como derecho humano. JURÍDICAS CUC, 15(1). 263-284. DOI: http://dx.doi.org/10.17981/juridcuc.15.1.2019.10

\section{Resumen}

Este artículo aborda el tema de la justicia alternativa como derecho humano de las personas, reconocido en los artículos $1^{\circ}$ y 17 de la Constitución Política de los Estados Unidos Mexicanos-EUM, exponiendo sus antecedentes y justificandola como derecho humano, realizando una crítica respecto a la carencia de programas o políticas públicas institucionales para divulgar la existencia de los diversos métodos de esta justicia para la solución de conflictos. Asimismo, se identifica como el acceso a ella, garantiza los procesos de transformación social, cultural y judicial en los que prevalece una cultura de paz y concordia basada en procesos de integración, participación e inclusión ciudadana en las instituciones, respetando y protegiendo la dignidad de todo individuo. La metodología utilizada fue el método deductivo, partiendo de lo general a lo particular se revisó la doctrina, las legislaciones y los criterios de interpretación publicados por el Poder Judicial de la Federación relacionado con este tema, de modo, con una técnica de investigación documental apropiada para este trabajo. Lo cual permitio identificar el alcance de la cultura de paz a partir de la aplicación sustantiva de la justicia alternativa desde el aspecto jurisdiccional y no jurisdiccional, la importancia de la profesionalización del facilitador, la necesidad de implementar desde diversos ámbitos la educación para la recomposición del sistema de justicia en México, así como considerar la formación educativa de los mecanismos alternativos para atender problemas en diversos ámbitos como ambiental, escolar, mercantil, pena y laboral, entre otros.

Palabras clave: acceso a la justicia; justicia; programa o política pública; derecho humano.

\section{Abstract}

This article addresses the issue of alternative justice as a human right of individuals, recognized in articles 1 and 17 of the Political Constitution of the United Mexican States-EUM, exposing its antecedents and justifying it as a human right, criticizing the lack of programs or institutional public policies to publicize the existence of the various methods of this justice for conflict resolution. Likewise, it is identified as access to it, it guarantees the processes of social, cultural and judicial transformation in which a culture of peace and harmony prevails, based on processes of integration, participation and citizen inclusion in institutions, respecting and protecting the dignity of every individual. The methodology used was the deductive method. From the general to the particular, the doctrine, legislation and interpretation criteria published by the Judicial Branch of the Federation related to this topic were reviewed, using a documentary research technique appropriate for this work. This made it possible to identify the scope of the culture of peace based on the substantive application of alternative justice from a jurisdictional and non-jurisdictional standpoint, the importance of the professionalization of the facilitator, the need to implement education for the re-composition of the justice system in Mexico from various spheres, as well as to consider the educational training of alternative mechanisms to address problems in various spheres such as environmental, school, commercial, punishment and labor, among others.

Keywords: Access to justice; justice; program or public policy; human right 


\section{INTRODUCCIÓN}

En México, el sistema de justicia que prevalece es a través del mecanismo heterocompositivo, es decir, el juicio, en el cual un tercero a través de una instancia jurisdiccional establece la resolución del caso mediante la repartición o distribución de los objetos o personas; siendo así, en la mayoría de las situaciones por no señalar en su totalidad, el conflicto se "resuelve" de esa forma, sin considerar en ningún momento a las personas autoras del conflicto. Esto nos lleva a considerar que el sistema de justicia se ha mantenido en un escenario de procesos tardíos, sin dar cumplimiento a su principio de ser rápido y expedito, toda vez que los procesos son tardados, costosos y burocratizados. Por ello, en el desarrollo de este artículo se expone a la Justicia Alternativa como aquella representante de la eficacia de un sistema de acceso a la justicia, por ser un derecho reconocido en la Ley Fundamental (1917), sin embargo, por el estudio tradicional y poca o nula aplicación de este sistema de justicia, regularmente o en su mayoría sólo se ha procurado efectuar el estudio de la jurisdicción del Estado.

En ese sentido, se resalta la pronunciación de un sistema de justicia alternativa, vista mediante mecanismos distintos a la tutela jurisdiccional en sentido estricto, pues, si bien en algunos casos la práctica de dichos métodos nace con ocasión de acceso del conflicto a los tribunales, ya sea para resolverlos o intentar remediarlos en el seno mismo del proceso, esto no implica que la solución se obtenga por la resolución de un juez, sino por la voluntad de las partes. En este sistema de justicia prevalece la participación de las partes y el tercero se ocupa de dirigir el procedimiento como agente de realidad social, fungiendo así como un puente de comunicación entre las partes, como ocurre en los métodos de conciliación, mediación, negociación autocompositivos, y en el arbitraje, donde el árbitro o tribunal arbitral sí tienen facultad de heterocomposición, pero está dentro de los métodos alternativos que rigen por la voluntad de las partes. 
Se plantea el derecho humano de acceso a la justicia desde la justicia alternativa, poniendo interés en procesos de información; divulgación de estos mecanismos para que la ciudadanía conozca de ellos y se transite a una cultura de paz y concordia. Más allá de eso este artículo subraya la necesidad de políticas públicas que apoyen en este proceso de transición dentro del propio sistema de justicia y como sociedad.

Por esto, el objetivo de este artículo enfatiza en acentuar la importancia de la aplicación en diversos programas o políticas públicas, encaminadas a la difusión y aplicación de la justicia alternativa como derecho humano, permitiendo así un mecanismo para integrar el sistema de justicia jurisdiccional y no jurisdiccional de forma sustantiva, lo que coadyuve a procesos de cambio y transición para una cultura de paz y concordia.

La importancia de este artículo esta en la necesidad de comprender como a partir de nuevas reformas constitucionales y creación de leyes en México, la justicia alternativa tiene mayor apertura, llegando a considerarse en las reformas de algunas leyes (laboral, civil, penal, mercantil, ambiental) como mecanismos dentro de los procesos jurisdiccionales para que las personas involucradas en un conflicto puedan llegar a un acuerdo de forma voluntaria, representando así una vía para agotar antes de llegar a un juicio. Por ello, la aplicación de políticas públicas o programas deben atender la integración o fortalecimiento de la justicia alternativa dentro de su desarrollo y planeación institucional.

Aunado a lo anterior, es importante reconsiderar que el acceso a la justicia alternativa ha estado previsto como un derecho humano, por lo que el conocimiento y difusión de estos temas en diversos aspectos, como el académico, permite fortalecer la divulgación de la justicia alternativa como derecho humano a todo ciudadano universal.

Este artículo está divido en dos partes, el primer apartado intitulado Justicia Alternativa, parte desde el interés de conocer y describir el acceso a la justicia desde el sistema de justicia ju- 
risdiccional y no jurisdiccional y el segundo acápite denominado Derechos Humanos, señala la garantía que se tiene desde el ámbito del derecho internacional el acceso a la justicia alternativa.

\section{Discusión}

\section{Justicia Alternativa}

A nivel internacional el acceso a la justicia está reconocido por las "Garantías Judiciales" de la Convención Americana sobre Derechos Humanos (OEA, art. 8, 1978), la cual establece todos aquellos principios y criterios que lo hacen legítimo, parte del derecho de toda persona a ser oída con las garantías y en un plazo razonable por la instancia competente; a la igualdad con garantías mínimas; a ser asistido sin costo en caso de requerir de un traductor o intérprete y a ser asistido o defenderse personalmente, entre otros. De igual forma establece derechos similares como:

Toda persona tiene derecho a ser oída, con las debidas garantías y dentro de un plazo razonable, por un juez o autoridad competente, independiente e imparcial, establecida con anterioridad por la ley, en la sustanciación de cualquier acusación penal formulada contra ella, o para la determinación de sus derechos y obligaciones de orden civil, laboral fiscal o de cualquier otro carácter (OEA, art. 8, sec. 1. 1978).

La Convención o Pacto de San José de Costa Rica (OEA, 1978) también señala la eficacia mediante la rapidez a prevalecer en el acceso a la justicia, misma que no puede violar derechos fundamentales ni ser pretensiosas a denegar o limitar ese derecho:

Toda persona tiene derecho a un recurso sencillo y rápido o a cualquier otro recurso efectivo ante los jueces o tribunales competentes, que la ampare contra actos que violen sus derechos fundamentales reconocidos por la Constitución, la ley o la presente Convención, aun cuando tal violación sea cometida por personas que actúen en ejercicio de sus funciones oficiales" (OEA, art. 25, 1978). 
En el Pacto Internacional de Derechos Civiles y Políticos (ONU, art. 14, 1966) se establece el derecho de toda persona en un plano de igualdad ante la justicia, a ser oída con las debidas garantías por un tribunal competente.

Se advierte que el Estado Mexicano ha reconocido el acceso a la justicia como un derecho fundamental; pero para que se concrete en la esfera jurídica de los gobernados, es necesario precisar que se manifiesta en dos aspectos complementarios: uno formal y otro material. El aspecto formal del acceso a la justicia se refiere a la obligación de las autoridades de dar respuesta de manera pronta, completa, imparcial y gratuita a las solicitudes de los particulares (partes en un procedimiento) respetando las formalidades del procedimiento; desde luego que ello no significa que necesariamente se resolverá en forma favorable a los intereses de la persona, sino sólo en los casos que en derecho proceda. Por su parte, el aspecto material del derecho de acceso a la justicia, complementa al primero, pues se refiere a la obligación de la autoridad de hacer cumplir sus resoluciones y, especialmente, cuando se trata de una sentencia definitiva o laudo que ha sido favorable a los intereses de alguna de las partes (EUM. Suprema Corte de Justicia-SCJ. Tribunales Colegiados de Circuito, 2011).

Por lo anterior, se resalta que en caso contrario al aspecto formal y material se tendría o continuaría con el carácter adjetivo o procesal.

El derecho de acceso a la justicia en el sistema mexicano ha sido objeto de grandes cambios en las últimas reformas, de trascendencia para el sistema de justicia fue la publicada el 18 de junio de 2008, en la cual se adicionó al artículo 17 constitucional un párrafo, donde dispone "las leyes preverán mecanismos alternativos de solución de controversias". A partir de esa fecha el sistema de acceso a la justicia para todas las personas incluye a la justicia alternativa. Este artículo Constitucional fundamenta la garantía individual de acceso a la impartición de justicia consagrada para los ciudadanos basada en los principios de justicia 
pronta, justicia completa, justicia imparcial y justicia gratuita (EUM. SCJ. Primera Sala, 2007), por lo cual se debe regir el Estado mexicano en cuanto el acceso a la justicia, estableciendo los mecanismos alternativos que privilegian las vías de solución de conflictos sobre los formalismos procedimentales.

En el nuevo paradigma de derecho de acceso a la justicia, las personas en situación de conflictos encuentran mayores posibilidades para buscar la solución, por una parte, además, el Derecho fundamental les brinda el acceso en la vía jurisdiccional a través de los jueces y autoridades previamente establecidas. Al respecto el Poder Judicial de la Federación, mediante jurisprudencia de la Primera Sala, ha definido el derecho a la jurisdicción como:

El derecho público subjetivo que toda persona tiene, dentro de los plazos y términos que fijen las leyes, para acceder de manera expedita a tribunales independientes e imparciales, a plantear una pretensión o a defenderse de ella, con el fin de que, a través de un proceso en el que se respeten ciertas formalidades, se decida sobre la pretensión o la defensa y, en su caso, se ejecute esa decisión (EUM. SCJ. Primera Sala, 2007).

Por otra parte, se considera importante detallar los mecanismos de la vía no jurisdiccional contemplados como auto compositivos los cuales son:

- Mediación. La Ley de acceso a la Justicia alternativa para el estado de Tabasco dispone que la mediación es un "Procedimiento asistido por un especialista que facilita la comunicación directa, respetuosa y confidencial entre las partes en el que sean ellos mismos quienes lleguen a un acuerdo voluntario que dé solución al conflicto" (Decreto 207, art. 3, frac, III, 2012). Es un método no adversarial, en el cual el facilitador denominado mediador es agente de realidad y puente de comunicación con el propósito de que sean las partes quienes llegan al acuerdo total o parcialmente de forma voluntaria y autónoma. En el proceso de mediación el mediador no propone soluciones. 
- Conciliación. La Ley de acceso a la Justicia alternativa para el estado de Tabasco, señala la conciliación como "Procedimiento en el que están inmersas las partes involucradas guiadas por un especialista que propone soluciones con el objeto de ir facilitando el diálogo y la búsqueda de acuerdos" (Decreto 207, art. 3, frac. II, 2012). La función del conciliador es facilitar la comunicación entre las partes, este profesional puede proponer, recomendar o sugerir puntos o acuerdos que las partes puedan considerar para el convenio y así poner fin de forma parcial o total a la controversia. Para Meza, Arrieta y Noil (2018), el conciliador provee herramientas a las personas en conflicto, que en autonomía buscarán solución pacífica a la circunstancia problemática.

- Arbitraje. Blanco (2013) describe que el arbitraje es un "Método de solución de conflicto en donde las partes se aseguran una solución, que no será logrado por ellas mismas, sino por un tercero profesional denominado "arbitro" dicha decisión a la solución se denomina laudo, el cual tiene carácter de obligatorio para las partes y excluye el concomiendo del conflicto a la jurisdicción". La flexibilidad de este mecanismo autocompositivo es como las partes solicitan y asisten de forma voluntaria al proceso, sin embargo, es un poco más limitada en el sentido que tienen que acatarse a lo que determine el árbitro. Maldonado y Montaña (2017) señalan que la emisión de laudo por parte de árbitros investidos con la facultad de administrar justicia tras la designación que las partes en el proceso realizan para tal fin, tiene plena validez en virtud de la norma constitucional, con lo cual pone fin a un proceso.

En mediación y conciliación las partes y un profesional colaboran para que sean las partes en cuestión los que construyan sus acuerdos conforme a sus intereses y necesidades el facilitador en cada mecanismo llega a tener sólo un grado de participación como ya se mencionó; en el arbitraje las partes las partes solicitan o aceptan el procedimiento acatándose al laudo. 
La justicia alternativa, es un sistema de justicia que tiene como propósito lograr un acuerdo entre los involucrados a través de la voluntad, la cooperación y el diálogo, permitiendo a las personas involucradas resolver sus problemas sin necesidad de ir con un juez, y además solucionar el conflicto de forma rápida y eficaz (EUM. Secretaría de Gobernación, 2016). Este nuevo enfoque de acceso a la justicia es reconocido por el Estado, ante la poca eficacia de los procedimientos jurisdiccionales, toda vez que la judicialización de los conflictos satura los tribunales y la justicia se vuelve tardía para las partes en conflicto, además del costo económico y desgaste emocional.

En México a partir de la reforma constitucional de 2008, se da pauta a un acceso a la justicia mediante mecanismos alternativos en pro de una cultura de paz y concordia en el sentido de posicionar a las personas como eje central de un nuevo sistema de justicia en el sentido social, jurídico, económico, político, cultural. Al respecto, con esta reforma el Estado remueve aquellos obstáculos normativos, sociales y económicos que impiden o limitan la posibilidad de tener acceso a la justicia como garantía de los derechos económicos, sociales y culturales.

Algunos de los aspectos o factores que inciden en que el acceso a la justicia no sea efectiva se menciona el costo económico, psicológico y físico que implica la justicia tradicional mal aplicada, así como sus procedimientos, deshumanización y el no tratamiento de despojo de las posiciones de las partes en conflicto, todos estos factores internos y externos tanto endógenos y exógenos hacen que la justicia para las personass no cumplan los principios constitucionales como el deber ser gratuita, completa y expedita. Sin embargo, el acceso a la justicia alternativa bajo el enfoque de los derechos humanos permite, a través de una justicia transicional, que los conflictos puedan ser abordados de forma inclusiva y participativa.

Con el objeto de reglamentar el derecho de acceso a la justicia alternativa posterior a la reforma constitucional, los Estados de 
la República de México reformaron sus constituciones locales, y legislaron para reglamentar la práctica de los mecanismos alternativos de solución de controversias. Como el reconocimiento de este nuevo enfoque de justicia se dio durante la reforma al nuevo sistema de justicia penal, a partir de diciembre de 2014, fue publicada la Ley Nacional de Mecanismos Alternativos de Solución de Controversias en Materia Penal (2014), toda vez que por disposición constitucional al tratarse de conflictos penales se debe cuidar la reparación del daño y la supervisión judicial, y en la justicia para adolescentes en conflicto con la ley, las formas alternativas de justicia deberán aplicarse, siempre que resulte procedente.

Los mecanismos de solución de controversias se rigen por principios de equidad, voluntariedad, neutralidad, honestidad, imparcialidad, confianza, justicia, que reconocen y legitiman a la ciudadanía mediante la participación activa. Foddai (2010) manifiesta que la expresión de alternativa es una expresión ampliamente difundida y empleada en ámbito internacional, desde Estados Unidos hasta Europa, desde Australia hasta Asia, designa un sistema de gestión de las controversias que se sirven de métodos informales y extraprocesales.

En materia penal la Justicia Restaurativa para el Estado de Sinaloa es descrita como:

Todo proceso en el que la víctima u ofendido y el imputado, participan conjuntamente, de forma activa, en la resolución de las cuestiones derivadas del delito, con la ayuda de un facilitador capacitado, en busca de un resultado restaurativo, en el que se privilegiará la reparación del daño (Decreto 831, art. 4, Frac. V, 2013).

En este sentido establece la participación de las partes quienes serán mediante el profesional denominado facilitador las que establezcan el resarcimiento de la acción o conducta que derivó en un daño. 
Finalmente, esta vía de solución de conflictos como describe Cobb (2016), tiene como propósito lograr un acuerdo entre los involucrados a través de la voluntad, la cooperación y el diálogo, significando una suma de voluntades, porque las partes están dispuestas a llegar a acuerdos que les favorecerán a través del apoyo de una persona neutral capacitada para encontrar una solución pacífica, es decir, un mediador, conciliador o árbitro. En ese contexto, es necesario decir que dichos mecanismos pueden ser empleados para resolver conflictos previamente de ir a la jurisdicción o en controversias que ya están en los tribunales pero que pueden ser resueltos por las partes a través de la voluntariedad.

\section{Derechos Humanos}

Los Derechos Humanos son el conjunto de prerrogativas inherentes a las personas humana, que le corresponden por el simple hecho de serlo, integrado por los derechos civiles y políticos, económicos, sociales y culturales, para que la persona tenga un desarrollo personal y vida digna. En consonancia en la Carta Magna mexicana en su artículo $1^{\circ}$, dispone que son Derechos Humanos de todas las personas los comprendidos en la Ley Fundamental, y en los tratados en los que México sea parte, reconociendo el derecho de protección más amplio en favor de las personas, de conformidad con los principios ${ }^{1}$ de

\footnotetext{
1 Universalidad, por ser derechos inalienables de todos los seres humanos sin distinción alguna de persona por ningún motivo de raza, edad, género, religión, salud, preferencias, ideas, condición física, económica, social y cultural. Interdependencia, la afectación o satisfacción de algún derecho llega a impactar a otros u otros derechos. Indivisibilidad, no se puede distinguir algún orden de importancia ya que se encuentran interrelacionados, no existe preeminencia entre los derechos otorgados. Progresividad, en una sociedad de constante y evolutiva transformación de la dinámica social estos derechos pueden llegar a ser expansivos de acuerdo a nuevas condiciones sociales que determinen la vigencia y necesidad de otras prerrogativas que deban ser reconocidas de forma favorable al sujeto.
} 
universalidad, interdependencia, indivisibilidad y progresividad. En consecuencia, "el Estado deberá prevenir, investigar, sancionar y reparar las violaciones a los derechos humanos..." (Oficina del Alto Comisionado para los Derechos HumanosOACNUDH, 2008) el contenido de este párrafo constitucional busca regular y solucionar los conflictos, respetando los derechos fundamentales, de forma relevante la dignidad humana (ONU, 1948).

En el Estado mexicano la dignidad humana se considera dentro del ordenamiento como un bien jurídico circunstancial al ser humano, merecedor de la más amplia protección jurídica, reconocido actualmente en los artículos 1o., último párrafo; 2o., apartado A, fracción II; 3o., fracción II, inciso c); y 25 de la Constitución Política de los Estados Unidos Mexicanos. Fungiendo, así como un principio jurídico que permea en todo el ordenamiento, pero también como un derecho fundamental que debe ser respetado en todo caso, cuya importancia resalta al ser la base y condición para el disfrute de los demás derechos y el desarrollo integral de la personalidad. Se trata de una norma jurídica que consagra un derecho fundamental a favor de la persona y por el cual se establece el mandato constitucional a todas las autoridades, e incluso particulares, de respetar y proteger la dignidad de todo individuo, entendida ésta en su núcleo más esencial como el interés inherente a toda persona, por el mero hecho de serlo, a ser tratada como tal y no como un objeto, a no ser humillada, degradada, envilecida o cosificada (EUM. SCJ. Primera Sala, 2016).

Los derechos humanos son derechos básicos, afirmaciones de la dignidad humana frente al Estado, son inherentes a toda persona afirmándose frente al poder público, en donde todos los seres humanos son titulares, no son objeto de negociación debido a que son absolutos, ya sea que un derecho humano puede desplazar a otro derecho humano o en su caso se adhieren, no puede ser renunciado por la propia voluntad del titular ya que son inalienables. En el caso del acceso a la 
justicia como reconocimiento de derecho humano está relacionado con momentos y contextos que lo han delimitado como tal, por mencionar casos en diversas materias que llevan años en un proceso de litigio constituyendo así una fuente jurídica en constante evolución.

El derecho de acceso a la justicia es un Derecho Humano previsto en la Constitución Política de los Estados Unidos Mexicanos (art. 17, 1917), de tal manera que la justicia alternativa mediante los mecanismos alternativos, corresponde a todas las personas y puede ser elegidos por quienes enfrentan una situación de conflictos para resolver sus controversias, estos métodos les permite tener una justicia pronta, completa, imparcial, gratuita y efectiva. Esta justicia a través de mediación, conciliación, negociación, arbitraje y justicia restaurativa se encuentran dentro del Derecho Humano, con la misma igualdad que el acceso a la jurisdicción del Estado, y pueden ser practicados válidamente siempre que sean procedentes y se encuentren reconocidos por la legislación. Silva (2014) señala que para hacer posible una cultura de convivencia remite a ubicar el conflicto en el contexto determinado, reconociendo sus elementos, propiedades y características para su prevención, atención y posible solución.

Aunado a lo anterior es importante señalar el reconocimiento de los derechos humanos a rango constitucional establecido en el artículo primero de la Constitución, por lo que a la par de los derechos humanos y el acceso a la justicia se da pauta para considerar con mayor relevancia la justicia alternativa ${ }^{2}$ lo que representa un proceso de reconocimiento, transición, complementación o integración de los mecanismos heterocompositivos y autocompositivos.

${ }^{2}$ No se contrapone con el derecho de acceso a la jurisdicción del Estado ya que establece dentro del mismo marco constitucional teniendo idéntica finalidad: solucionar los conflictos. 
La justicia alternativa mediante mecanismos no judiciales está siendo considerada como agente de cambio y paz social ${ }^{3}$ (SEGOB, SER, ONU, 2014) ejemplo de ello es el Estado de Michoacán que promueve la cultura de paz mediante la prevención con la Ley para la Cultura de Paz y Prevención de la No Violencia (Decreto 169) ${ }^{4}$ la cual está basada en la inclusión social y la Ley de Cultura Cívica del Distrito Federal (2004) basada en propiciar y desarrollar la convivencia armónica, la corresponsabilidad entre habitantes y autoridad en conservación de espacios de convivencia, el diálogo, el respeto por la diferencia y diversidad, el sentido de pertenencia a la comunidad y la colaboración como vertiente del mejoramiento del entorno y calidad de vida. Sin embargo, a pesar de estar reconocida en la Constitución Federal como un sistema de acceso a la justicia y que los Estados antes mencionados establezcan leyes que coadyuvan la función de estos mecanismos, todavía hay carencia de programas o políticas públicas institucional para divulgar y hacer saber a todas las personas que es su derecho de elegir las vías alternas de solución de conflictos.

Esta afirmación deriva del hecho que, si bien hay vigente en el país más de veintinueve leyes estatales que regulan la práctica de los mecanismos, pero la implementación de este sistema de justicia es incipiente y lenta, porque los poderes judiciales estatales, se siguen apropiando del acceso a la justicia, y en el caso también lo quieren hacer con los mecanismos.

\footnotetext{
${ }^{3}$ En el periodo de la presidencia de la república del Lic. Enrique Peña Nieto se tenía contemplado dentro de sus metas nacionales, la de tener un "México en Paz" integrada por los temas de seguridad, derechos humanos, gobernabilidad, democrática, rendición de cuentas y corrupción, entre otros.

4 Esta Ley está basada en los principios de conciliación, continuidad, Derechos Humanos, diálogo, diversidad, equidad, integridad, intersectorialidad, interdisciplinariedad, mediación, proximidad, solidaridad, tolerancia, trabajo conjunto, transparencia y rendición de cuentas y transversalidad.
} 
La escasa legitimación social y cultural de la justicia alternativa se manifiesta por la carencia de algunos aspectos como:

a. La formación de profesionales en ese sistema de justicia, que tengan la preparación y competencias para ser mediadores, conciliadores, árbitros, negociadores y especialistas en Justicia Restaurativa. Para lo cual, es deseable que en los planes y programas de estudio de licenciaturas y/o posgrado se enseñe y capacite en métodos de solución de conflictos, no sólo en la formación de licenciados en derecho, sino en todas las disciplinas como una asignatura transversal, toda vez que esos métodos son apropiados para abordar controversias de índole civil, familiar, mercantil, penal, comunitario, escolar, medio ambiente, ocupación de la tierra, compras virtuales, energético, incluyendo los casos de adolescentes en conflicto con la ley, como lo considera por ejemplo la Ley de Mecanismos Alternativos de Solución de Controversias en el Estado de Yucatán (Decreto 212, art. 3, 2009).

b. Políticas públicas dirigidas a todas las personas donde se les informe y fortalezca que es un derecho que tienen para elegir esas vías para solucionar sus conflictos o controversias, bajo los principios base que Baruch y Folger (2006) contemplan, los cuales son la voluntad, confidencialidad, flexibilidad, neutralidad e imparcialidad, equidad, legalidad, consentimiento informado, entre otros, de esta forma será un programa de alcance preventivo a situaciones de conflicto emergente, latente y manifiesto, así como en violencia.

c. Ampliar y poner al alcance de todas las personas centros o institutos de acceso a la Justicia Alternativa, un tipo de justicia itinerante en la cual no sean propiamente los establecidos en los juzgados o tribunales de justicia, ni los centros de justicia de las fiscalías estatales o procuradurías de justicia; es decir, que sean espacios neutrales atendidos por profesionales en métodos de solución de conflictos debidamente certificados, que participen con las partes en conflictos y los guíen en los procedimientos de mediación, conciliación, etcétera. Siendo 
así procesos de capacitación, formación continua y profesionalización de expertos facilitadores en mecanismos de solución de controversias.

d. Reconsiderar mediante la justicia alternativa la vía para alcanzar una cultura de paz que no sirvan solamente como mecanismos de solución de conflictos sino como prevención, lo cual se puede lograr desde la formación de sectores comunitarios como la divulgación en centros escolares, delegaciones, vecindarios, centros o áreas en donde las personas se congregan, entre otros. Considera un proceso de reintegración social a partir de contextos específicos de las comunidades o localidades, en el sentido que se trabajaría con todos los sectores de la sociedad permitiendo así la difusión y aplicación de los mecanismos de forma progresiva, sustantiva e integral.

Paulatinamente, en algunas entidades federativas se trabaja en la certificación, profesionalización y especialización de mediadores, como ocurre en la Ciudad de México donde hay más de quinientos setenta y un (571) mediadores privados certificados, como lo señala el Tribunal Superior de Justicia de la Ciudad de México (TSJCDMX, 2019). En el sistema de justicia penal hay registros de INEGI (Instituto Nacional de Estadística y Geografía) que en el país existen 228 Centros de Justicia Alternativa, operando en las procuradurías o fiscalías locales de acuerdo al Censo Nacional de Impartición de Justicia (INEGI, 2016).

Definitivamente, se requiere trabajar en divulgar temas relacionados con la Justicia Alternativa a efectos de alcanzar el propósito que sea un derecho efectivo a todas las personas que, bajo los principios de voluntariedad, flexibilidad y el deseo de resolver sus controversias las personas puedan solucionar su controversia en el marco de la Justicia Alternativa prevista en el artículo 17 Constitucional. 


\section{Conclusiones}

La justicia alternativa representa el fortalecimiento de acceso a la justicia como mecanismo autocompositivo, está reconocido en la Constitución Política de los Estados Unidos Mexicanos (art. 17, 1917), por tanto, como derecho humano, su aplicación debe ser garantizada en un plano de igualdad como el derecho de acceso a la jurisdicción, porque ambos sistemas persiguen el mismo fin, que las personas resuelvan sus conflictos. Aunque a través de la justicia alternativa, el conflicto es resuelto por las propias personas protagonistas del conflicto. Además, este sistema de justicia también tiene la finalidad de coadyuvar a la cultura de paz, sobre todo que las personas a través del diálogo y negociación resuelven sus conflictos, mediante el consenso, el acuerdo, el reconocimiento y el respeto al otro.

El proceso educativo y formativo de la justicia alternativa y cultura de paz en los diversos contextos sociales, requiere ser implementada y fortalecida en planes y programas de estudio en los diversos sectores educativos. En el caso del nivel medio superior y superior es importante señalar la inclusión de asignaturas para la enseñanza bajo un esquema transversal de mecanismos alternativos de solución de conflictos, de cultura de paz, cultura de la legalidad. En el caso de la formación profesional se requiere mayor aprendizaje porque en todas las profesiones hay conflictos, y el profesional requiere por lo menos de conocimientos para ser mediadores, conciliadores, negociadores; además, de los profesionales expertos en justicia restaurativa, que requiere la sociedad para conocer esta otra vía de acceso a la justicia.

La implementación de políticas públicas encaminadas a la paz social y sistema de justicia efectiva debe atender en la difusión y divulgación a través de programas accesibles a toda la población, en el cual se enfatice en la justicia alternativa, como vía para atender y resolver sus controversias a través de métodos no jurisdiccionales como la mediación, conciliación, negociación, 
arbitraje y la justicia restaurativa. La vía de la jurisdicción es una más y explicar los principios que rigen dichos mecanismos como la voluntariedad, la flexibilidad, la imparcialidad, la neutralidad la confidencialidad, la equidad y la igualdad de las partes, permite que la ciudadanía considere una vía pacífica de solución de conflicto.

Por último, se destaca que el sistema de justicia en México transita en una recomposición, pues, su replanteamiento gira en el reconocimiento del catálogo más amplio en Derechos Humanos, así que incorporar a la Justicia Alternativa implica que el abanico de acceso a la justicia para las personas sea amplio, mirando este derecho desde una óptica horizontal (de igualdad y equidad con las partes) a como se miran y se estudian los Derechos Humanos. Los mecanismos de solución de controversias propician la participación ciudadana, asumiendo como señalan Hernández, Alvarado y Chumaceiro (2013) por parte de los ciudadanos el compromiso con el objeto de mejorar las condiciones de vida, considerando así también las necesidades de los otros, creando y fortaleciendo redes de solidaridad y compromiso social para fines colectivos en bien común, de forma tal que se articula la relación del Estado y sociedad con y desde una perspectiva ciudadana con elementos y características basadas en sentido humano, solidario, diverso, e inclusivo. De forma tal que estos mecanismos otorgan ventajas y beneficios en cuanto a procedimiento y resolución de sus conflictos, así como en el cumplimiento de sus acuerdos, asistidos por un tercero profesional quien facilita la comunicación, progresando así en la implementación de una justicia horizontal.

\section{REFERENCIAS}

Baruch R. A., Bush y Folger, J. P. (2006). La promesa de la mediación, como afrontar el conflicto a través del fortalecimiento propio y el reconocimiento de los otros. Buenos Aires: Granica. 
Blanco, M. (2013). Mediación y sistemas alternativos de resolución de conflictos. Una visión jurídica. Madrid: Reus.

Cobb, S. (2016). Hablando de violencia, la política y las poéticas narrativas en la resolución de conflictos. Barcelona: Gedisa.

Distrito Federal. Asamblea Legislativa. (31 de mayo de 2004). Ley de cultura cívica del distrito federal. Gaceta Oficial del Distrito Federal: 31/05/2004.

Estado de Michoacán. Congreso del Estado. (26 de septiembre de 2016). Ley para Una Cultura de Paz y Prevencion de la Violenciay la Delincuenciaen Michoacan. [Decreto 169]. Periódico Oficial del Estado de Michoacán de Ocampo, 63. Recuperado de http://www.poderjudicialmichoacan. gob.mx/web/igualdadgenero/contenido/legislacion/ Ley\%20para\%20una\%20Cultura\%20de\%20Paz\%20 y\%20Prevención\%20de\%20la\%20Violencia\%20y\%20 la\%20Delincuencia\%20en\%20Michoacán.pdf

Estado de Sinaloa. Congreso del Estado. (15 de mayo de 2013). Ley de Justicia Alternativa en materia penal para el Estado de Sinaloa. Artículo 4. Fracción V. [Decreto 831]. Periódico Oficial "El Estado de Sinaloa" No. 059. Recuperado de http://www.transparenciasinaloa. gob.mx/images/stories/ARCHIVOS\%20PUBLICOS/ Leyes\%20Estatales\%20Actuales/2013/Ley_ JusticiaAlternativa.pdf

Estado de Tabasco. Congreso del Estado. (29 de agosto de 2012). Ley de acceso a la justicia alternativa para el estado de Tabasco. [Decreto 207]. Periodico Oficial Sup. D: 7302 Estado de Yucatán. Congreso del Estado. (24 de julio de 2009). Ley deMecanismosAlternativos deSolución deControversias en el Estado de Yucatán. Artículo 3. [Decreto 212]. DO: 24/07//2009. Recuperado de http://www.cjyuc.gob.mx/ marcoLegal/leyes/leymediosalternos.pdf 
Estados Unidos Mexicanos. Congreso Constituyente. (1917). Constitución Politica de los Estados Unidos Mexicanos. [Ley Fundamental]. Diario Oficial de la Federación: 05-02-1917. Recuperado de http://www.diputados.gob. $\mathrm{mx} /$ LeyesBiblio/ref/cpeum.htm

Estados Unidos Mexicanos. Congreso General. (29 de diciembre de 2014). Ley nacional de mecanismos alternativos de solución decontroversias en materia penal. DOF: 2912-2014. Recuperado de http://www.diputados.gob.mx/ LeyesBiblio/pdf/LNMASCMP_291214.pdf

Estados Unidos Mexicanos. TSJCDMX. (2019). Directorioweb. Recuperado de http://www.poderjudicialcdmx. gob.mx/cja/wp-content/uploads/DIRECTORIOWEB-22-04-19.pdf

Estados Unidos Mexicanos. Secretaria de Gobernación. (febrero 9, 2016). ¿Qué es la Justicia Alternativa?. [Blog]. Disponible en https://www.gob.mx/segob/articulos/ que-es-la-justicia-alternativa-19298

Estados Unidos Mexicanos. Suprema Corte de Justicia. Primera Sala. (26 de agosto de 2016). Dignidad humana. Constituye una norma jurídica que consagra un derecho fundamental a favor de las personas y no una simple declaración ética. [Tesis Jurisprudencial 1a./J. 37/2016 (10a.)]. Gaceta del Semanario Judicial de la Federación. Libro 33. (p. 633).

Estados Unidos Mexicanos. Suprema Corte de Justicia. Primera Sala. (1 de abril de 2007). Garantía a la tutela jurisdiccional prevista en el artículo 17 de la constitución política de los estados unidos mexicanos. Sus alcances. [Tesis Jurisprudencial 1a./J. 42/2007]. Semanario Judicial de la Federación y Gaceta del Semanario Judicial de la Federación, Tomo XXV. (p. 125). 
Estados Unidos Mexicanos. Suprema Corte de Justicia. Tribunales Colegiados de Circuito. (mayo de 2011). Derecho de acceso a la justicia previsto en el artículo 17 de la constitución federal. Se respeta en la medida en que se atienden los aspectos formal y material en que se manifiesta. [Tesis Jurisprudencial 162163. XXXI.4 K]. S.J.F. y Gaceta del Semanario Judicial de la Federación, Tomo XXXIII. (p. 1105).

Foddai, M. A. (2010). Conciliación y mediación ¿modelos diferentes de resolución de conflictos? En,E. Vásquez, J. Tomillo y L. García (Coord.), Mediación, arbitraje y resolución extrajudicial de conflictos en el siglo XXI (pp. 41-62), Madrid: REUS.

Hernández, J., Alvarado, L. y Chumaceiro, A. C. (2013). Estado, gestão pública e participação cidadã desde a modernidade e pós-modernidade. Gestión y Gerencia, 7(1), 66-80.

INEGI. (2016). Censo Nacional de Impartición de Justicia. Recuperado de https://www.inegi.org.mx/programas/ cnije/2016/

Maldonado, M. y Montaña, L. (2017). Arbitraje: mecanismo alternativo de solución de conflictos o privatización judicial. Jurídicas CUC, 13(1), 121-146. http://dx.doi. org/10.17981/juridcuc.13.1.2017.6

Meza, A., Arrieta, M. y Noil S. (2018). Análisis de la conciliación extrajudicial civil en la Costa Atlántica colombiana. Jurídicas CUC, 14(1), 187-210. http:// dx.doi.org/10.17981/juridcuc.14.1.2018.9

OEA. (18 de julio de 1978). Convención Americana sobre Derechos Humanos (Pacto de San José). Disponible en https:// www.oas.org/dil/esp/tratados_B-32_Convencion_ Americana_sobre_Derechos_Humanos.pdf 
ONU. (1948). Preámbulo. Declaración Universal de los Derechos Humanos. [Resolución 217 A (III)]. Recuperado de https://www.ohchr.org/EN/UDHR/Documents/UDHR_ Translations/spn.pdf

ONU. (16 de diciembre de 1966). Pacto Internacional de Derechos Civiles y Políticos. [Resolución 2200 A (XXI)]. Disponible en https://www.ohchr.org/SP/ ProfessionalInterest/Pages/CCPR.aspx

OACNUDH (2008). Propuesta de reforma constitucional en materia de derechos humanos, elaborada por organizaciones de la sociedad civil y por académicas $y$ académicos especialistas en derechos humanos. México, D.F.: ONU.

SEGOB, SER, ONU. (2014). Manual y Protocolo para la Elaboración de Políticas Públicas de Derechos Humanos conforme a los nuevos principios constitucionales: Programa con perspectiva de Derechos Humanos en México. México, D.F.: ONU.

Silva, F. (2014). Mediación comunitaria como mecanismo alternativo para el tratamiento de conflictos en pueblos indígenas. Mediación y Derechos Humanos. México, D.F.: Porrúa. 
Francisca Silva Hernández es Doctora en Métodos de Solución de Conflictos y Derechos Humanos y Maestra en Resolución de Conflictos y Mediación con Licenciatura en Sociología y en Derecho. Línea de investigación: Desarrollo sostenible, medio ambiente, justicia efectiva y derechos humanos. Universidad Juárez Autónoma de Tabasco (México). https://orcid.org/00000003-3533-0002

Germán Martínez Prats es Doctor en Gobierno y Administración Pública, Maestro en Contaduría Pública y Licenciado en Comercio Internacional. Línea de investigación: Estudios contables y administrativos. Universidad Juárez Autónoma de Tabasco (México). https://orcid.org/0000-0001-6371-448X 